\title{
Monitoring Ocular Disease by Impression Cytology
}

\author{
G. G. W. ADAMS ${ }^{1,3}$, P. N. DILLY ${ }^{2}$ and C. M. KIRKNESS ${ }^{3}$ \\ London
}

\begin{abstract}
Summary
The technique for obtaining and processing conjunctival impression cytology is described. The method of grading the stained samples is outlined. Our findings in various ocular conditions with particular emphasis on; alkali burns, uveitis, hypopyon ulcer and Botulinum toxin protective ptosis are shown. Cytology from severely damaged eyes is highly abnormal, improving as the ocular disease settles. In alkali burns a return to normal cytology does not correlate with return of corneal clarity. Loss of goblet cells is a common finding in the ocular diseases demonstrated, and appears to be a non-specific indicator of ocular problems.
\end{abstract}

In 1977 Egbert et al. reported a method of "simple conjunctival biopsy" using Millipore filters, originally with the aim of looking at goblet cell secretions. ${ }^{1}$ They found that they often obtained a sheet of cells from the ocular surface as the filter was removed from the eye. This surface biopsy specimen can then be stained to reveal the cells, and goblet cell secretions. ${ }^{2}$ There is evidence to suggest that the limbal conjunctival epithelium may be important in corneal re-epithelialisation after injury. ${ }^{3}$ The stem cells are thought to arise from the palisades of Vogt, become transformed into transient amplifying cells that become incorporated ${ }^{4}$ into the basement layer of the corneal epithelium. ${ }^{5}$ These cells then give rise to the other layers of the corneal epithelium. It has been suggested that some corneal epithelial abnormalities may be the result of limbal conjunctival problems. This has given rise to the concept of "pan ocular surface disease". In many cases of corneal surface disease, corneal biopsy is not justified or is contra-indicated, and it is in these situations that a simple, safe, noninvasive, method of assessing corneal and conjunctival morphology would be of considerable advantage. Using impression cytology, which is simple, non-invasive and non- traumatic we have looked at a variety of ocular conditions. By taking repeated samples over the course of a disease process we have been able to monitor the progress of that disease. By following the course of an ocular surface disease we have observed the changes in cellular morphology which we had hoped would be useful in defining what occurred in the course of various disease states and in predicting the efficacy or otherwise of various treatment regimes.

\section{Material and Methods}

Millipore filters GS $0.22 \mu \mathrm{m}$ were used. Most filters have a smooth, shiny surface, and a dull, matt one. The latter was used as it adhered better to the epithelium and therefore picked up a better sheet of cells. The filter was placed on the surface of the eye, using plain forceps so as not to damage it, massaged gently against the ocular surface using a glass rod, removed from the surface using forceps and placed in $95 \%$ ethanol.

Correspondence to: CM Kirkness, Professorial Unit, Moorfields Eye Hospital, City Road, London, EC1.

Departments of ${ }^{1}$ Ophthalmology and ${ }^{2}$ Anatomy, St. George's Hospital Medical School, London, SW17 0RE, and ${ }^{3}$ Cornea Clinic, Moorfields Eye Hospital, City Road, London, EC1V 2PD.

Presented at the Annual Congress of the Ophthalmological Studies of the United Kingdom, April 1988. 
This solution is a good fixative for cellular morphology, it has the advantage that the filter and adherent cells can remain in it for some time before being processed.

After the procedures were explained to the patient samples were taken from four areas when possible:- medial and lateral, bulbar conjunctiva within the interpalpebral fissure area, inferior bulbar conjunctiva and the superior tarsal conjunctiva (with the upper lid everted).

In the laboratory the filters were removed from the alcohol, and rehydrated with distilled water before being stained with PAS (for goblet cell secretions), and haematoxylin (for epithelial cells). They were then dehydrated through a graded series of alcohols and xylene, before being mounted on glass slides using Eukitt.

The samples were then examined using light microscopy, and graded on a scale of $0-$ 3 depending on epithelial and goblet cell morphology (Fig $1-4)$. In addition the presence or absence of inflammatory cells was noted (Fig 5). It was also possible to assess the quality of cell sheet obtained.

The following classifications were used:-

Grade 0: Small, round epithelial cells with a nucleus to cytoplasm ratio of $1: 2$. Lots of deeply stained goblet cells (as shown by the intensely PAS positive staining intracellular mucin of the goblet cells). A good confluent sheet of cells was usually obtained.

Grade 1: A good cell sheet consisting of larger epithelial cells with a decreased nucleus to cytoplasm ratio (1:3). Goblet cells are slightly reduced in number but still deeply stained with PAS.

Grade 2: Larger epithelial cells, with a further decrease in nucleus to cytoplasm ratio. A reduced number of goblet cells, often with reduced staining.

Grade 3: Large irregular epithelial cells, with small nuclei. Few goblet cells, which tend to stain palely. Normally poor sheets of cells are obtained, and often only loose clumps of cells can be seen.

The changes from grade 0 to 3 are, of course, the features that represent squamous metaplasia of the conjunctival epithelium.

\section{Results}

We found that if the conjunctiva was chemo- tic or the eye very watery the filters did not stick as well to the ocular surface, giving a poor sample. If the shiny side of the filter was used instead of the dull side a good sheet of cells was not obtained. This surface did not appear to stick well to the eye. If a large sheet of filter paper was used it was often difficult to place it against the surface of the eye again resulting in a poor sheet of cells. Routinely, we used haematoxylin and PAS stains. However other stains can be used. Care needs to be taken in placing the coverslip over the stained filter to avoid air bubbles. Differences between samples were apparent when examined under low power. Higher magnification was useful in obtaining a more detailed picture.

\section{Alkali Burns (Figs. 6 and 7).}

In the acute stages of alkali burn a poor sample for cytology is often obtained, especially when the conjunctiva is chemotic, since the filter does not adhere well to the ocular surface. It may be that in severely damaged eyes the surface cells had not survived and did not therefore adhere to the filter paper. However, those cytological samples obtained show loose metaplastic cells with no goblet cells. Polymorphs are not normally seen grade 3 .

With time and treatment the cells return to a more normal morphology and goblet cells reappear. In one chronic case where the visual acuity was reduced to counting fingers due to scarring and vascularisation the picture on impression cytology was normal with a good population of goblet cells. It would appear that once the cornea became reepithelialised the cytology became more normal. Corneal epithelial integrity does not necessarily correlate with clarity.

\section{Uveitis (Figs. 8 and 9)}

In uveitis a good sheet of cells was regularly obtained with a fairly normal population of epithelial cells. There were virtually no goblet cells to be seen in most of the cytology samples. Inflammatory cells, mainly neutrophils, and occasional lymphocytes were seen in some specimens in the acute stage. The absence of goblet cells persisted well into the convalescence period, when the iritis had 


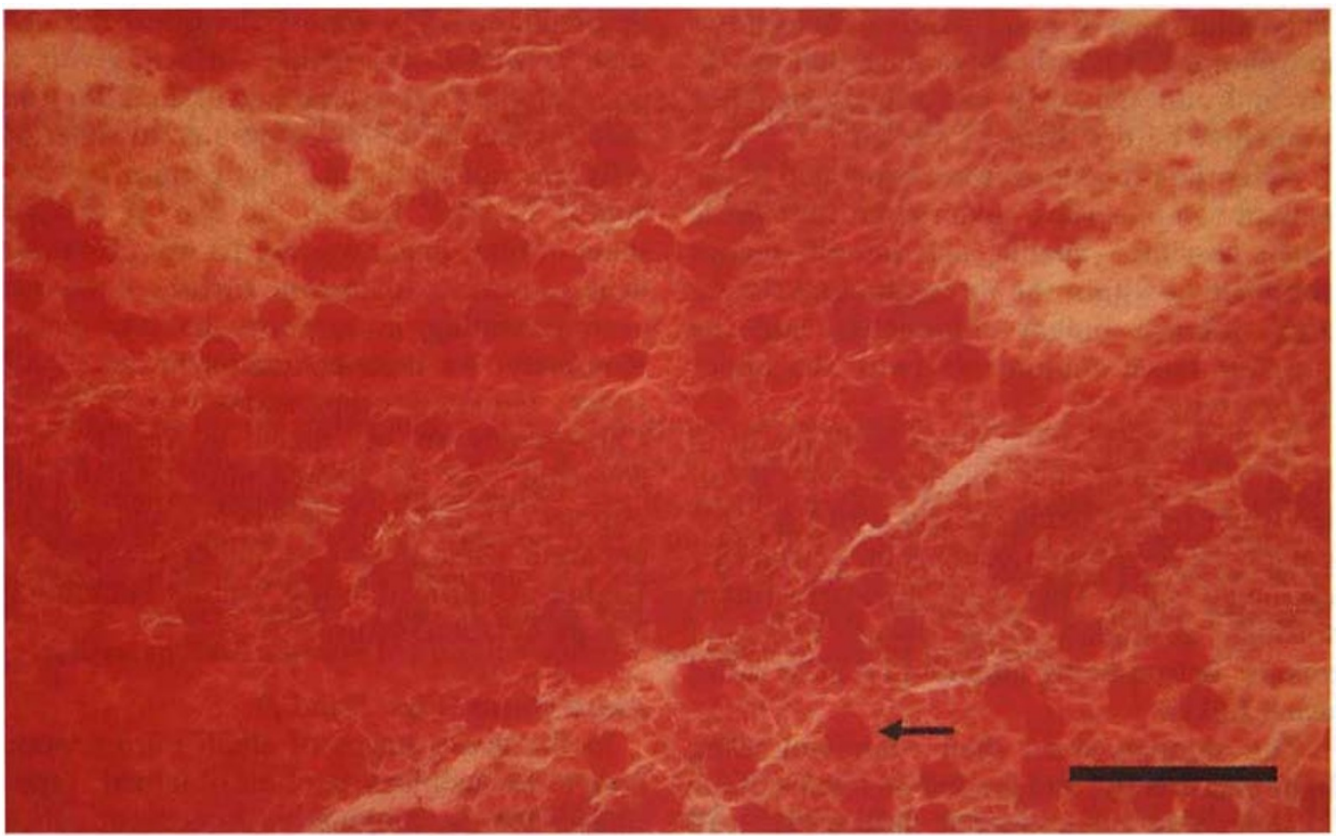

Fig. 1. Grade 0. Normal size and shape of epithelial cells. Note plump, well staining goblet cells (arrow). $P A S$ and haematoxylin stained. Bar $=100 \mu \mathrm{m}$.

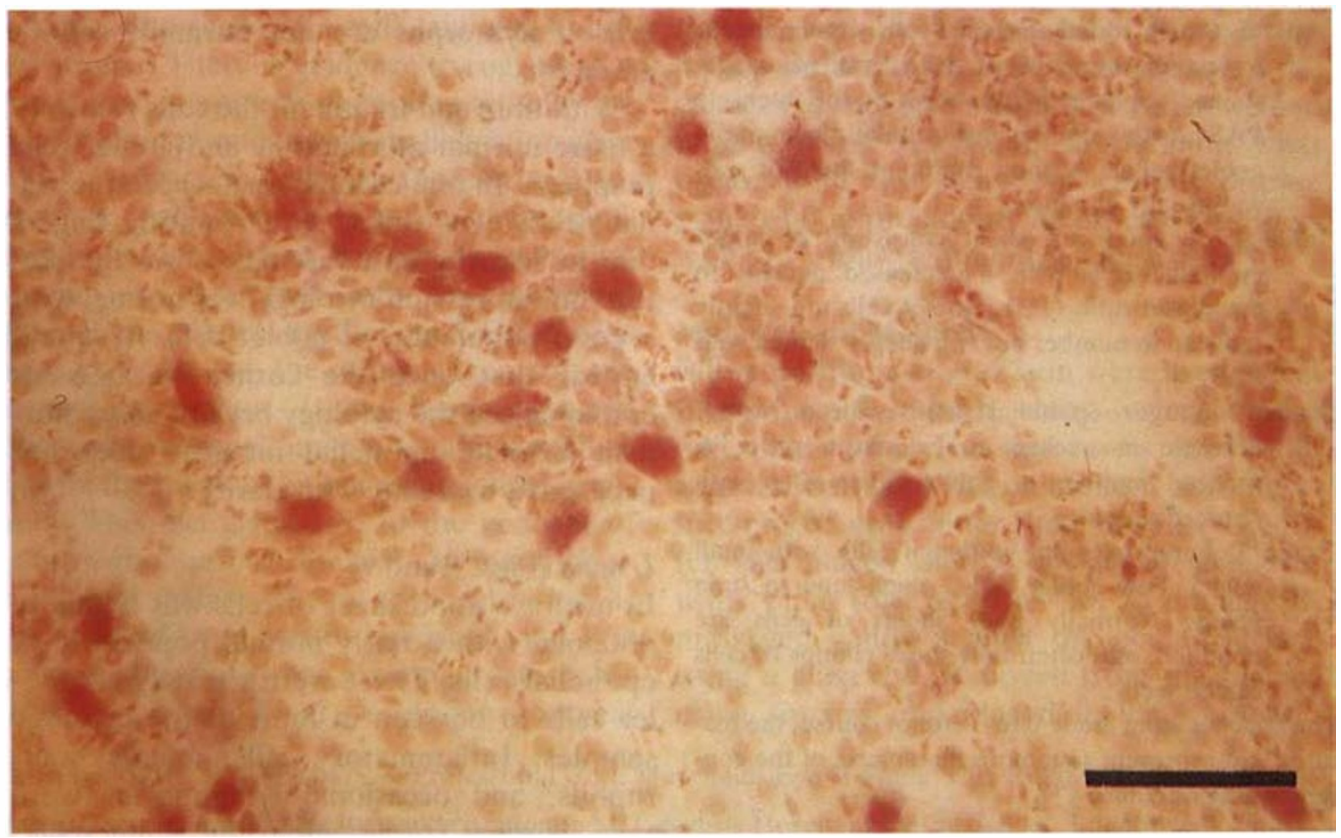

Fig. 2. Grade 1. Epithelial cell layer normal with increased amount of cytoplasm. Note reduced number and size of goblet cell population. PAS and haematoxylin stained. Bar $=100 \mu \mathrm{m}$. 


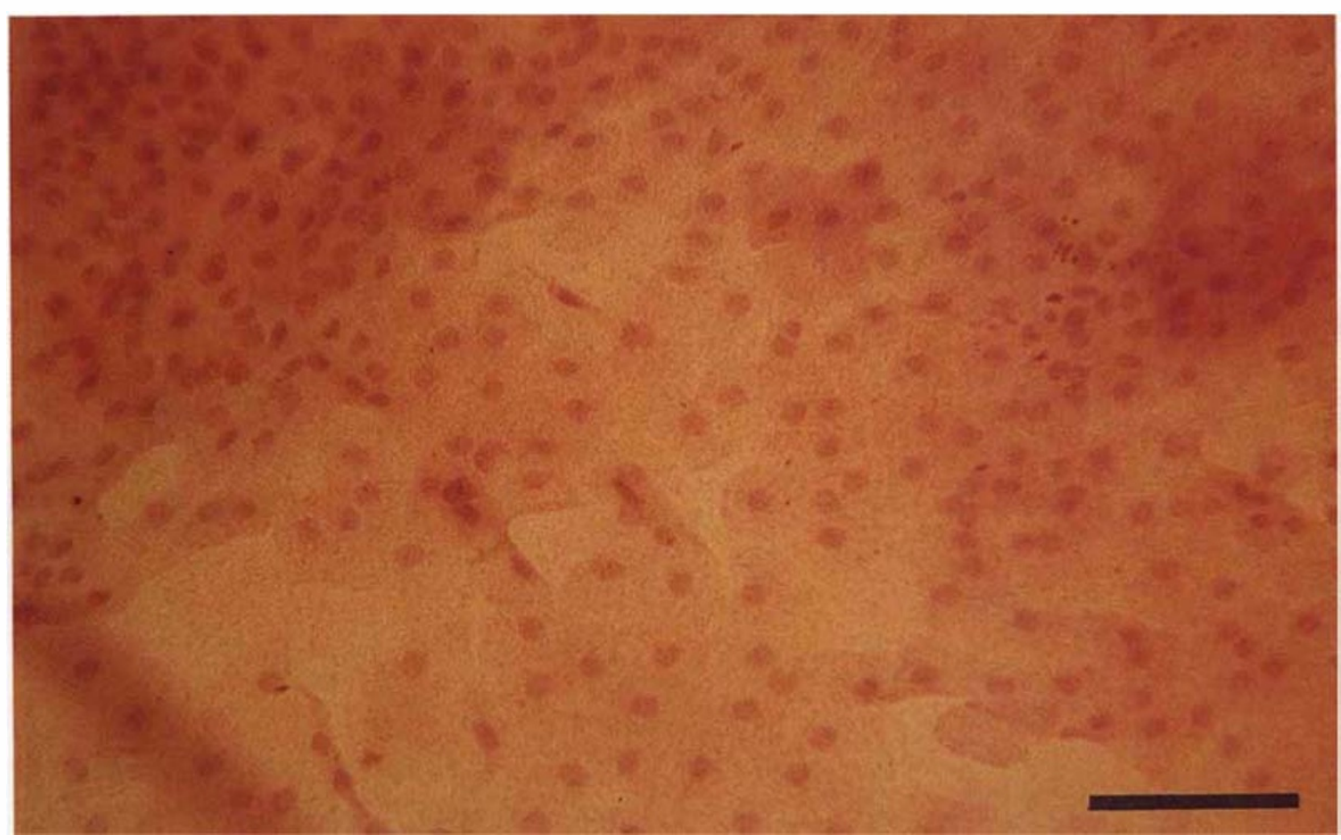

Fig. 3. Grade 2. Larger than normal epithelial cells, with an increased amount of cytoplasm. PAS and haematoxylin stained. Bar $=100 \mu \mathrm{m}$.

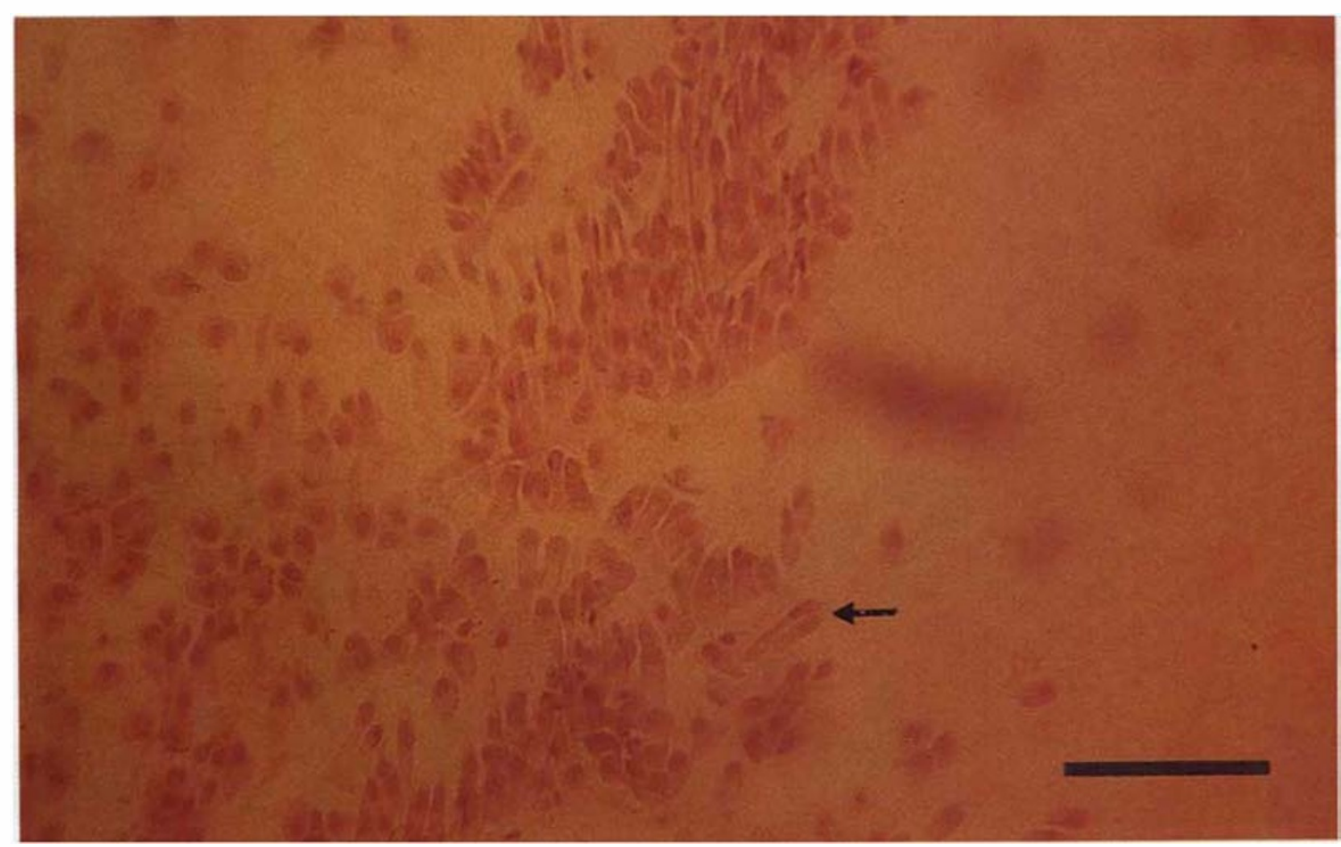

Fig. 4. Grade 3. Long elongated epithelial cells (arrowed) some loose cells, no goblet cells. PAS and haematoxylin stained. Bar $=100 \mu \mathrm{m}$. 


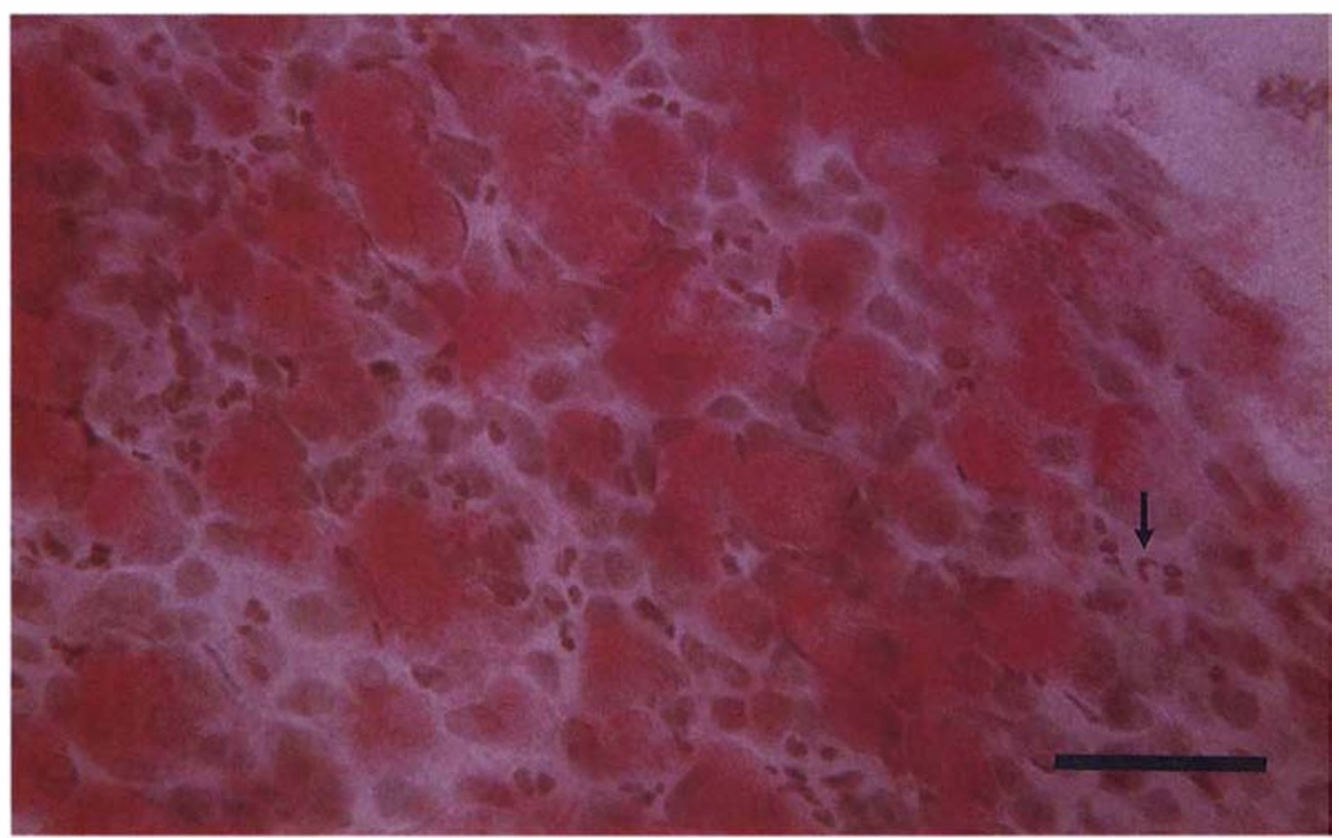

Fig. 5. Polymorphs. Arrow indicates one of the many polymorphs in this illustration. PAS and haematoxylin stained. Bar $=20 \mu \mathrm{m}$.

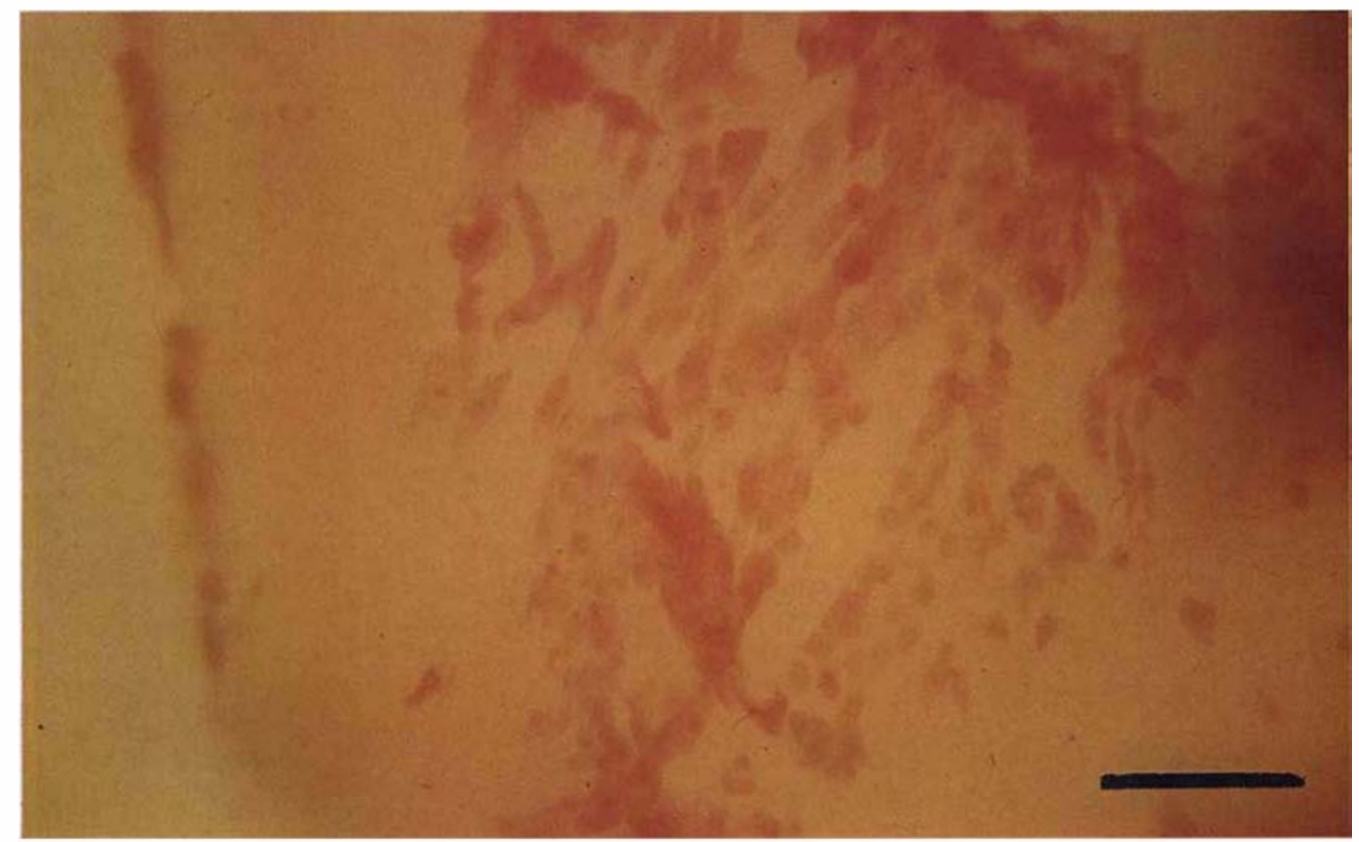

Fig. 6. Acute alkali burn. Long elongated dysplastic epithelial cells. No goblet cells. PAS and haematoxylin stained. Bar $=100 \mu \mathrm{m}$. 


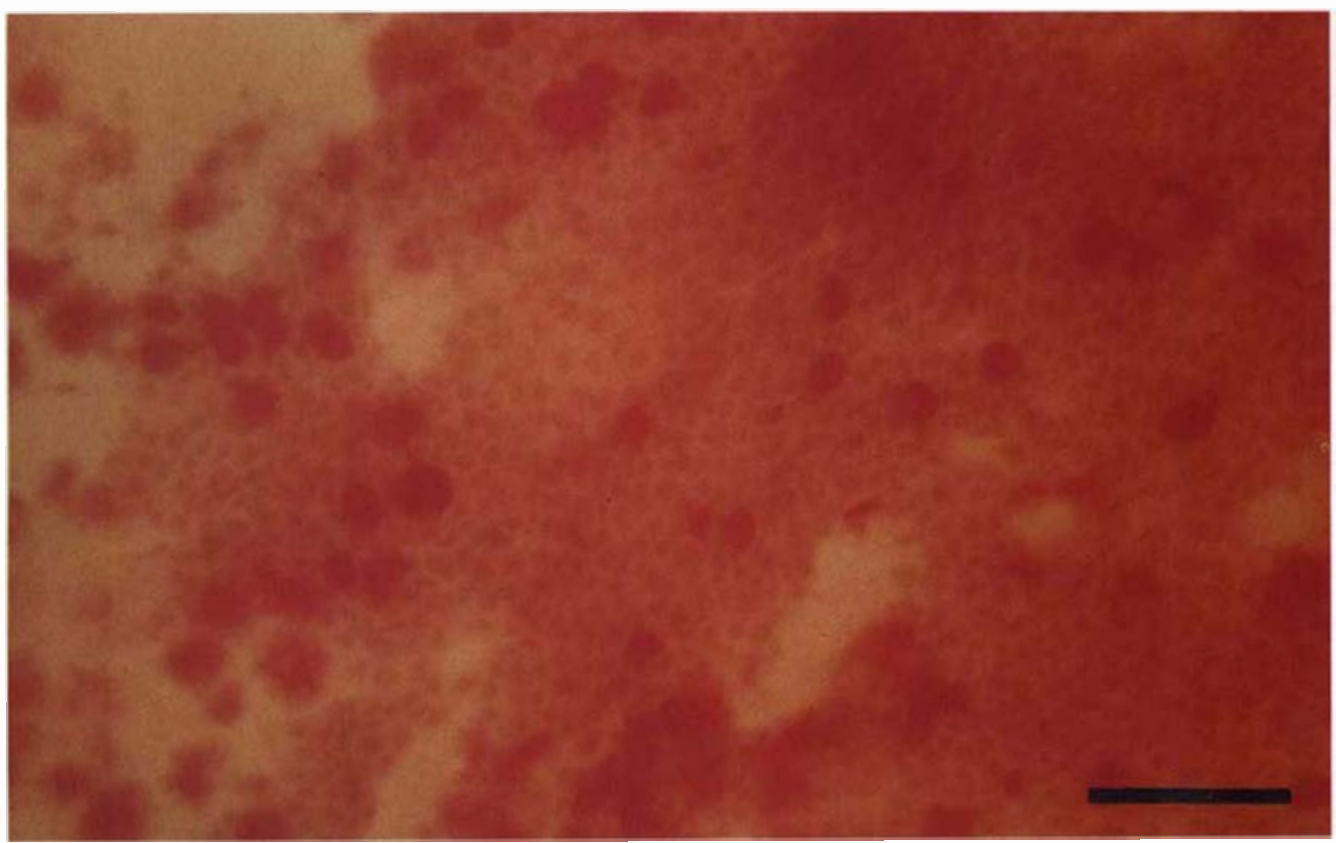

Fig. 7. Chronic alkali burn. Good sheet of epithelial cells. Goblet cells are present in reasonable quantity. $P A S$ and haematoxylin stained. Bar $=100 \mu \mathrm{m}$.

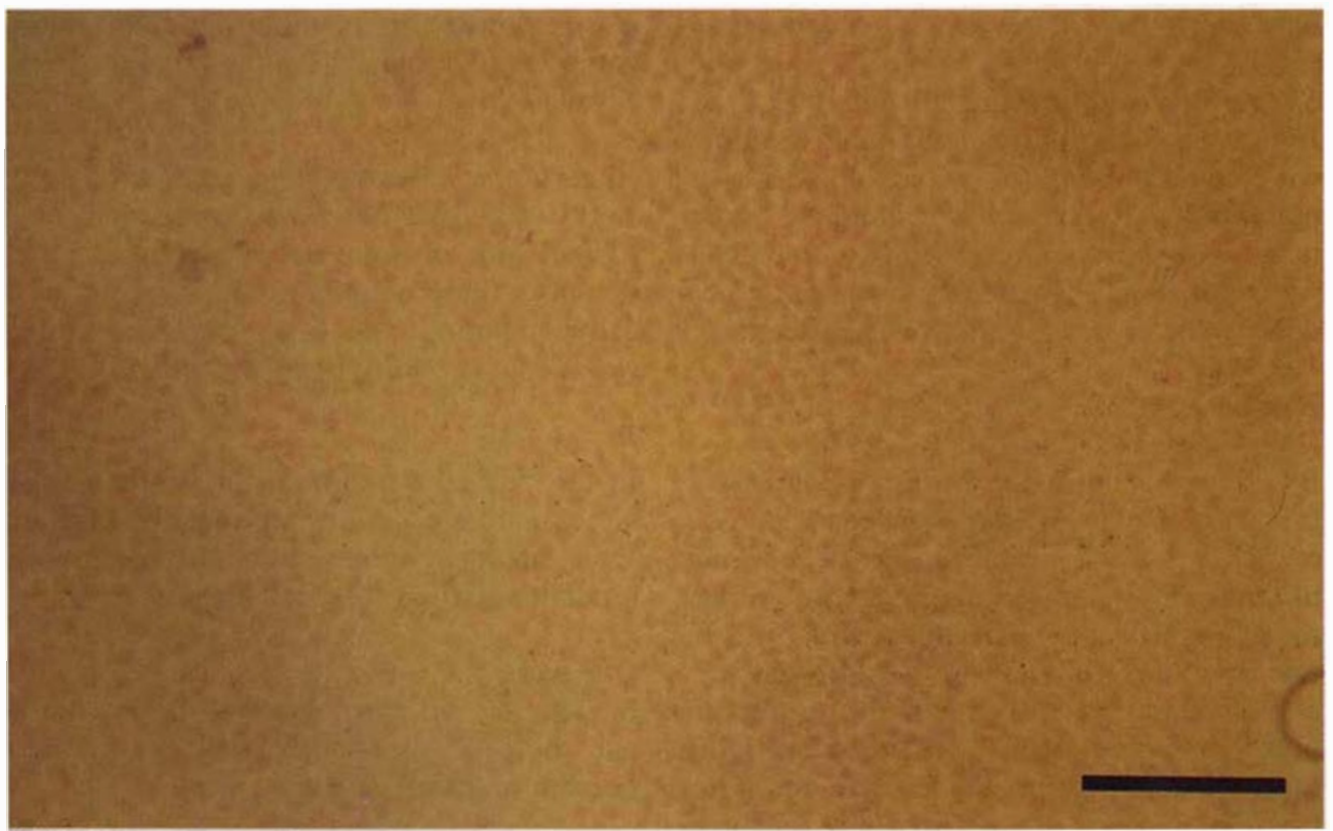

Fig. 8. Acute uveitis. Note the absence of goblet cells, but a good sheet of normal sized epithelial cells. $P A S$ and haematoxylin stained. Bar $=100 \mu \mathrm{m}$. 


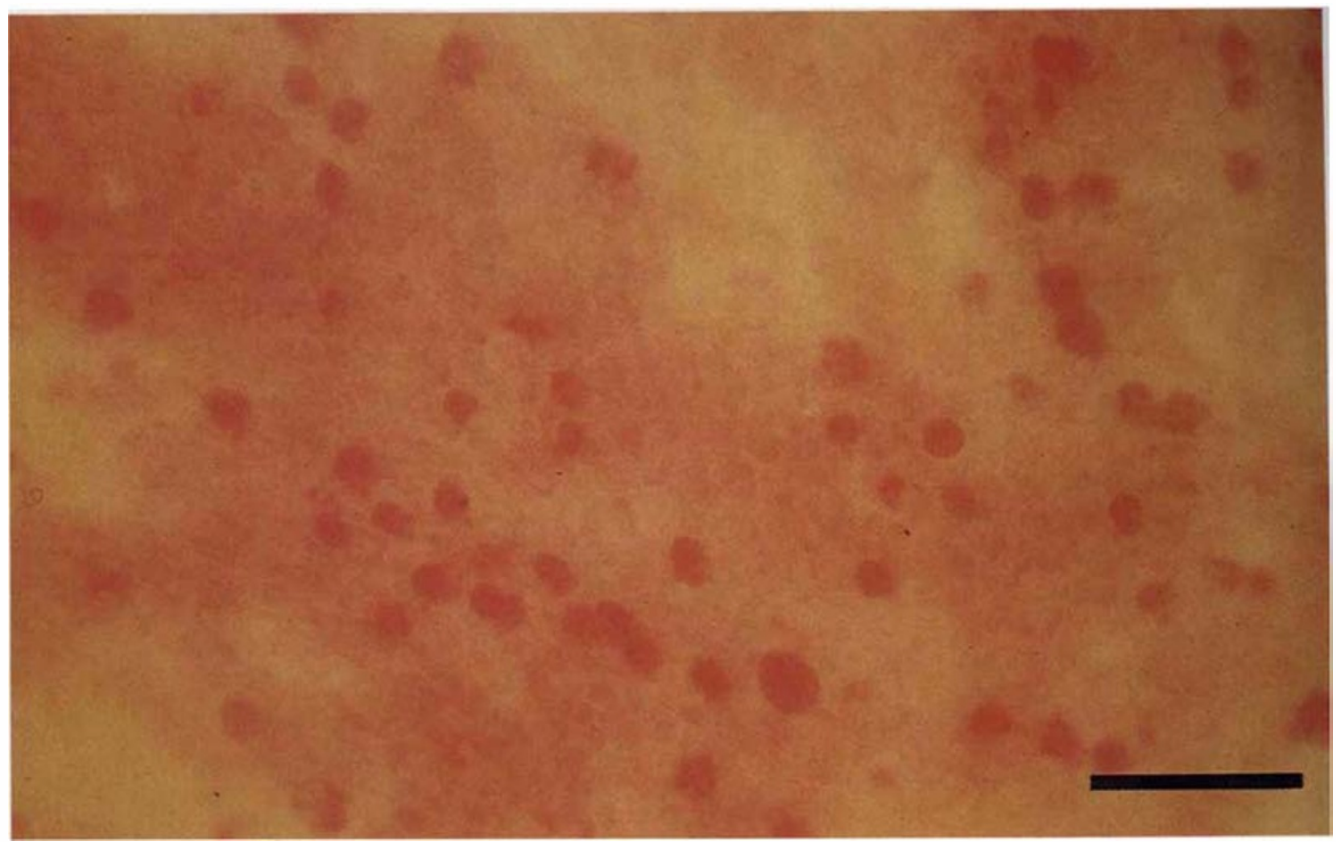

Fig. 9. Resolving uveitis. Epithelial cells with larger than normal goblet cells also reduced a little in number and size. PAS and haematoxylin stained. Bar $=100 \mu \mathrm{m}$.

almost resolved. As the inflammation settled the goblet cell population returned to normal.

\section{Suppurative keratitis (Figs 10 and 11)}

In the early acute stages poor quality samples were common, with only a few loose abnormal epithelial cells being obtained. Very many polymorphs were seen. Goblet cells were not found. These features were considered to be more of a grade 3 classification.

\section{Botulinum toxin protective ptosis (BTPP)} (Figs. 12 and 13)

BTPP has been previously described as a useful method of providing temporary corneal coverage for vulnerable corneas. ${ }^{6}$ Its main use has been in treating indolent corneal ulcers, and prophylactically in patients with corneal exposure. Despite the different variety of conditions for which the botulinum protective ptosis was performed we have found an improvement in cytology after treatment, except in the case where the ptosis was prophylactic and the cytological appearances remained unchanged as might be pre- dicted. In some cases the results were dramatic with an improvement from a grade 3 sample to a grade 1 in only four days, correlating with a rapid clinical improvement in the cornea.

\section{Acute atopic keratoconjunctivitis (AKC)}

In the only case that we have examined, in a patient with an acute red eye from a flare up of AKC, there was a fairly normal epithelial cell population, but once more the sample revealed an absence of goblet cells.

\section{$F^{3} T$ toxicity}

In the one case sampled, there was a slight increase in size of the epithelial cells, and some sites had some, although not marked, reduction in the goblet cell density.

\section{Dryeyes}

In general the cytology was unremarkable but some of the samples show a reduced number of goblet cells.

\section{Blepharoconjunctivitis}

In the samples from this condition the epithe- 


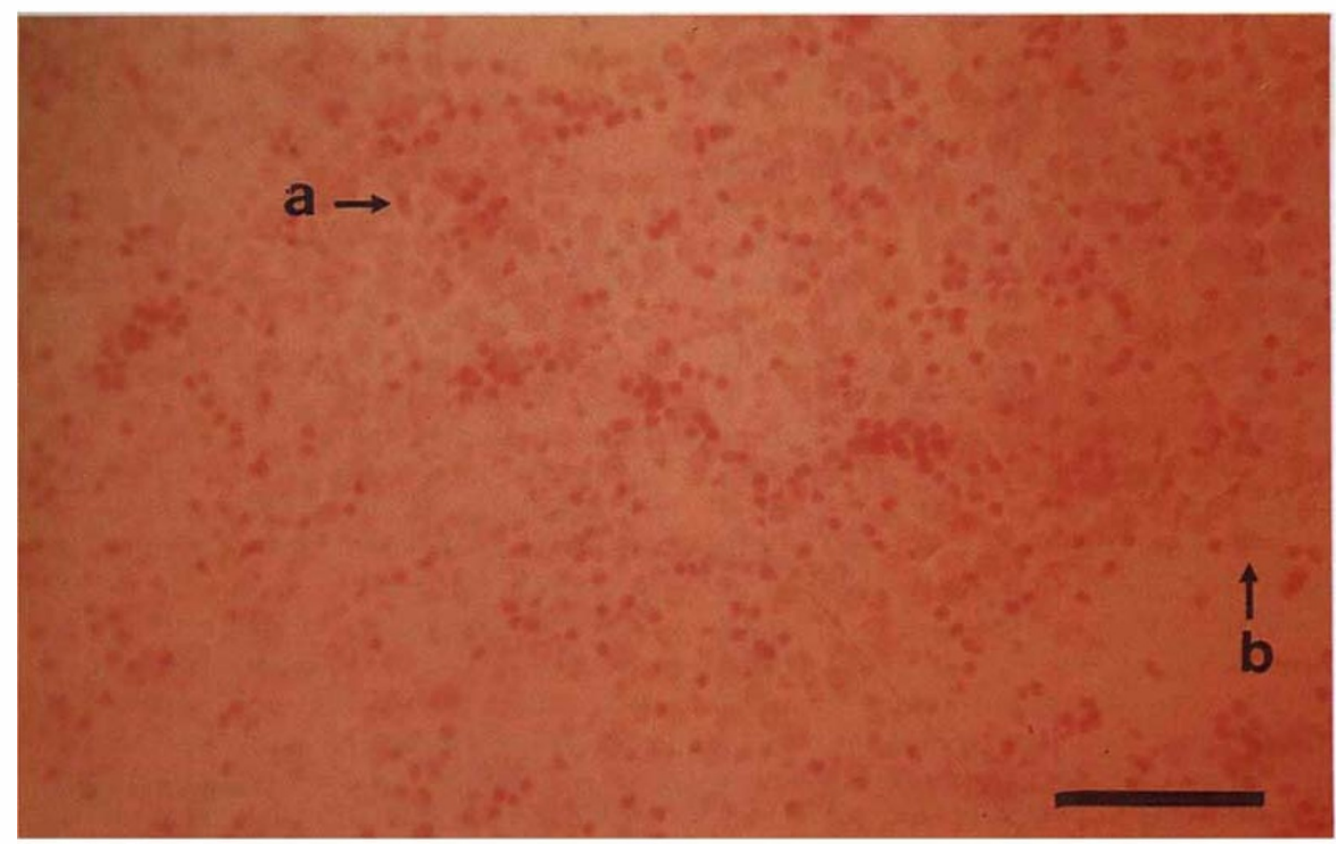

Fig. 10. Acute suppurative keratitis. Lots of inflammatory cells (a) larger than normal epithelial cells with poorly defined nuclei (b). PAS and haematoxylin stained. Bar $=100 \mu \mathrm{m}$.

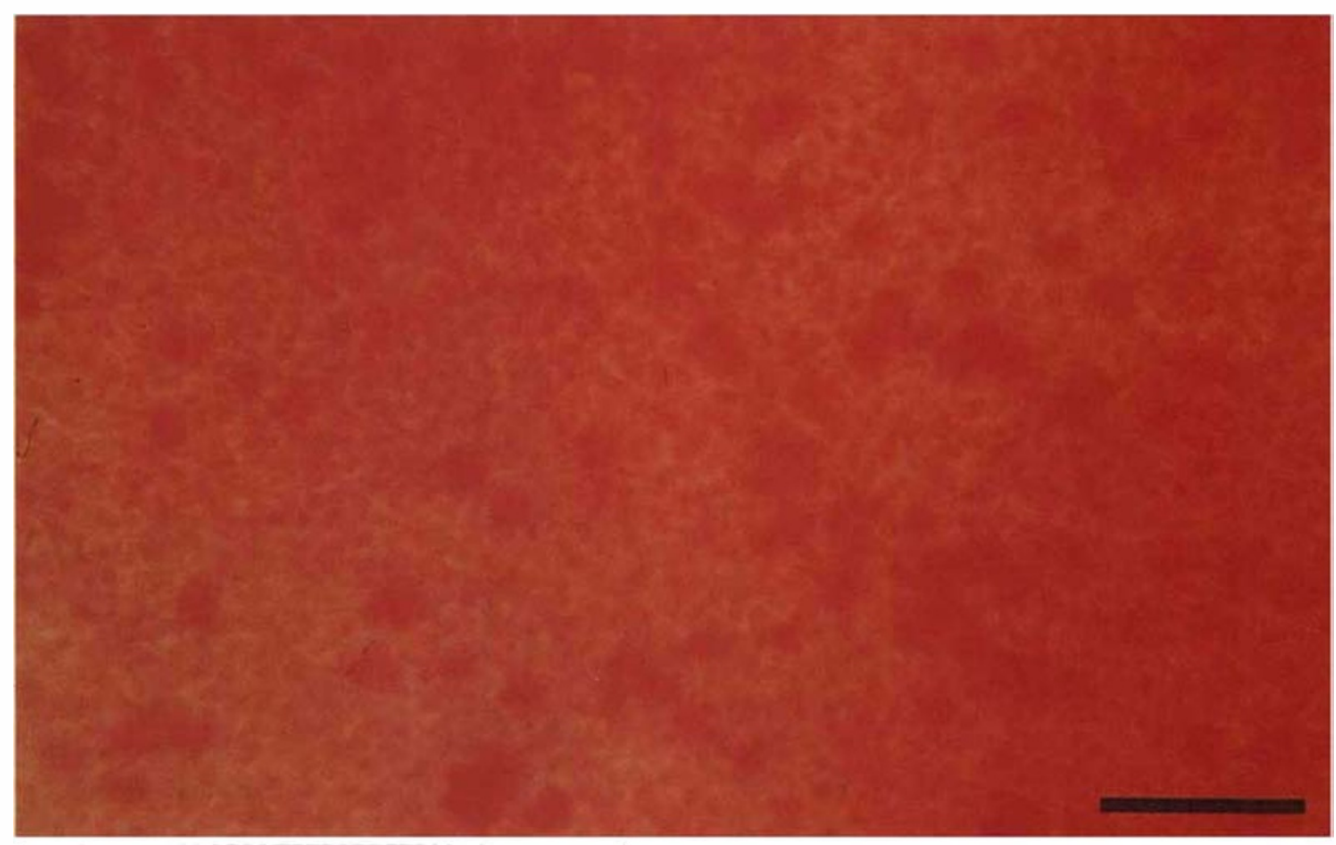

Fig. 11. Resolving suppurative keratitis. Goblet cells have returned. PAS and haematoxylin stained. Bar $=100 \mu \mathrm{m}$. 


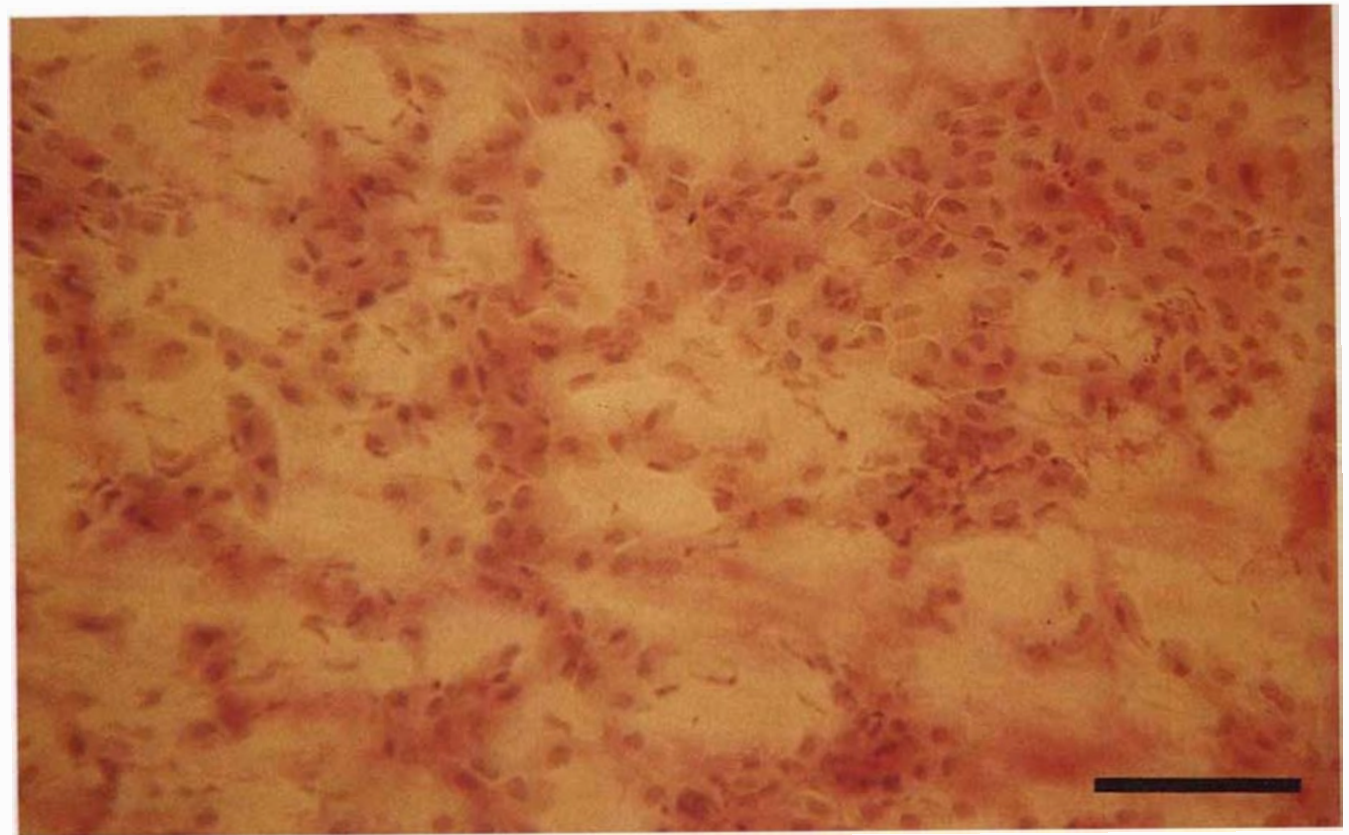

Fig. 12. Pre-BTPP. Poor sheet of dysplastic epithelial cells. PAS and haematoxylin stained. Bar $=100 \mu \mathrm{m}$.

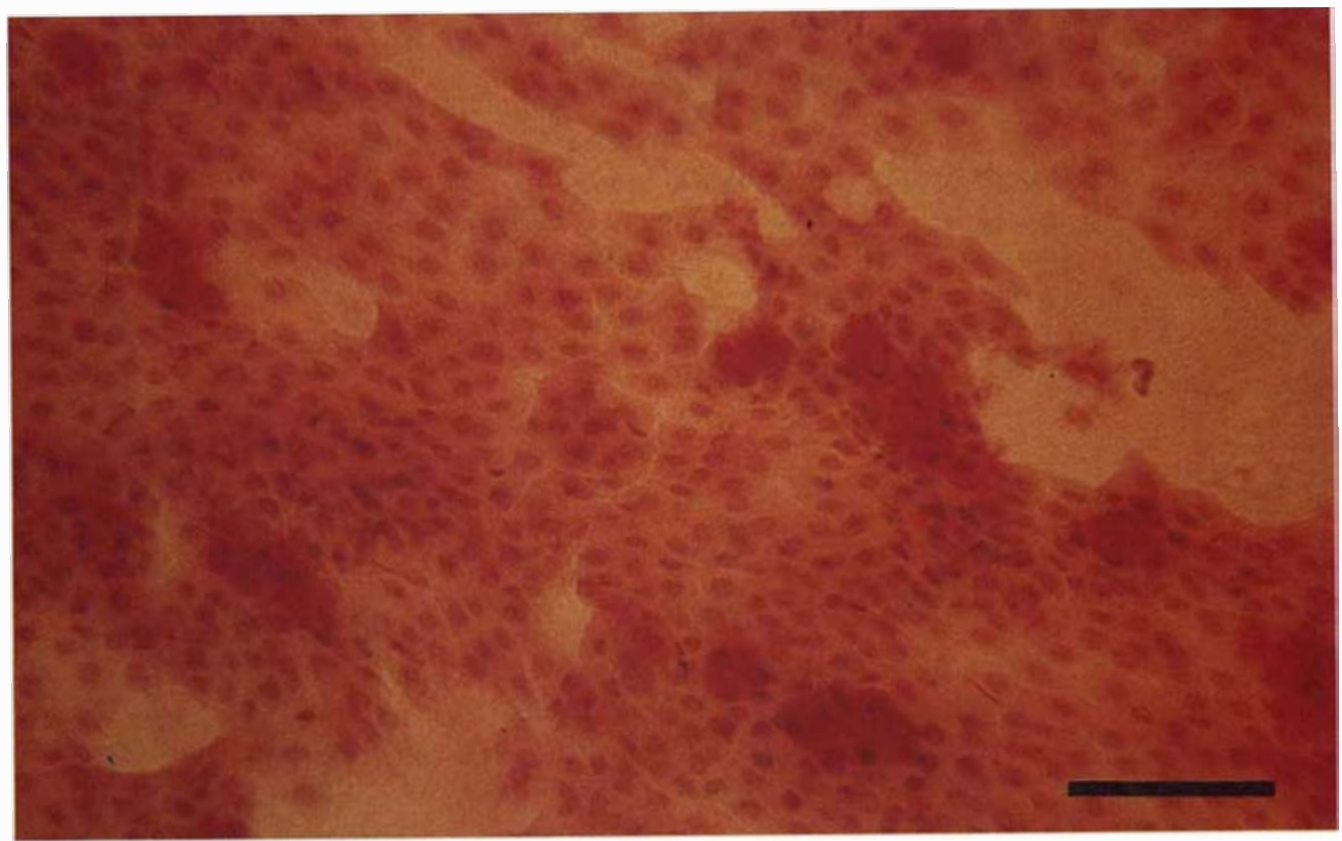

Fig. 13. Post-BTPP. Epithelial cells still a little larger than normal, but much improved morphology. Goblet cells present. PAS and haematoxylin stained. Bar $=100 \mu \mathrm{m}$. 
lial cell morphology varies with patches of slightly larger than normal epithelial cells and on some filters there was a reduction in goblet cells.

\section{Discussion}

Our results are presented in a qualitative rather than a quantitative form. Some authors have given quantitative details, however we feel that the filter paper adheres to such a small area, and the area of sample obtained is so variable that this is probably not very useful. ${ }^{7}$ We have found in our samples, that cytology of severely damaged eyes was highly abnormal, improving as the disease state improved. What was interesting, was the sensitivity of the goblet cell population to disease. Loss of these cells seemed to be a non-specific indicator of ocular problems. ${ }^{8,9}$ The reason for this is unclear, especially in the white eyed uveitic.

It has been shown that loss of vascularisation secondary to chronic cicatricial change, and inflammation is associated with a loss of goblet cells. ${ }^{10}$ Loss of vascularity and the presence of inflammation may have an important effect on epithelial differentiation, since loss of goblet cells is and important early sign of squamous metaplasia. Why loss of vascularity and the presence of inflammation should influence goblet cells is unclear, although this has been used as evidence to suggests the existence of a blood borne factor which is important for goblet cell differentiation. If the corneal epithelium does derive from the limbal conjunctiva then it is obviously important to know what happens to this area in ocular disease. Whether or not an abnormal conjunctival epithelium can result from changes to the cornea is not clear, since the epithelium undergoes differentiation (in the absence of vascularity) in the cornea. It would appear reasonable however if there was some effect from sub optimal conjunctival epithelial health or stability on the corneal integrity. Impression cytology provides a method of examining the conjunctival epithelium with causing trauma. It should, therefore, be considered as a useful additional method of examining the ocular surface.

The mucin secretion from the goblet cells is vital for stabilising the tear film, and although none of our patients appeared to have dry eyes, and many had distinctly watery eyes from the irritation of their ocular condition, it would seem likely in view of the fact of their reduced goblet cell populations that these tears must have been deficient in mucin, and that the ocular surface must have been bathed with an abnormal and unstable tear film. Presumably this must affect the health of the eye.

The return of goblet cells in chronic burns is interesting, as it is said that the loss of goblet cells with a consequent loss in mucin affects the pre-ocular tear film. In our chronic cases there was not much cicatricial change in the conjunctiva, but there was marked vascularisation, which may be important in view of the finding of others who have shown good density of goblet cells in a conjunctival flap from a chronic alkali burn which was very vascular but inactive at the time of sampling. In our worst alkali burn followed over several months, the goblet cells returned as the eye became settled, although there is marked corneal vascularisation and the patient is still on topical steroid treatment.

Inflammation is known to be associated with a reduction in the goblet cell population. A reduction in vascularity is also associated with a reduced goblet cell density. Normal conjunctiva is very vascular, and it has been. suggested that the maintenance of normal goblet cell population depends on this high degree of vascularity, and this has been used to explain why conjunctival epithelium transforms into corneal epithelium once it moves onto the avascular corneal surface. It is; therefore, very surprising that there should be an absence of goblet cells in the presence of an acutely inflamed eye and, especially therefore, associated with a highly vascular conjunctiva. This may, of course, be related to the altered permeability of the inflamed vessels. It is possible to stain the cells on the surface of the Millipore filters with a variety of stains. For example, it is possible to Gram stain them to look for infecting organisms. Whilst not being an alternative to corneal scrapes for a bacteriological diagnosis, it can be a useful adjunct. 
Impression cytology is a simple, non traumatic method for examining the surface of the conjunctiva, and it is useful in providing indirect assessment of the corneal epithelium. Different stains of the filters may provide us with further information.

\section{References}

${ }^{1}$ Egbert PR, Lauber MA, Maurice DM: A simple conjunctival biopsy. Am J Ophthalmol 1987; 84: 798-801.

${ }^{2}$ Nelson JD, Havener VR, Cameron JD: Cellulose acetate impressions of the ocular surface. Dry Eye States. Arch Ophthalmol 1983; 101: 1869-72.

${ }^{3}$ Shapiro SM, Friend J, Thoft RA: Corneal reepithelialization from the conjunctiva. Invest Ophthalmol Vis Sci 1982; 21: 135 42.

${ }^{4}$ Lemp MA, Guimaraes RG, Mahmood MA, Wong S, Blackman $\mathrm{HJ}$ : In vivo surface mor- phology of the human cornea by colour microscopy.Cornea 1983; 6: 295-97.

${ }^{5}$ Bron AJ: Vortex patterns of the corneal epithelium. Trans Ophthalmol Soc UK 1973; 93: $455-72$.

${ }^{6}$ Adams GGW, Kirkness CM, Lee JP: Botulinum toxin $\mathrm{A}$ induced protective ptosis. Eye 1987; 1: 603-8.

${ }^{7}$ Nelson JD, and Wright JC: Impression cytology of the ocular surface in keratoconjunctivitis sicca. In Holly FJ ed The preocular Tear Film Dry Eye Institute, Lubbock Texas 1986: 14052.

${ }^{8}$ Kinoshita S, Kiorpes TC, Friend J, Thoft RA: Goblet cell density in ocular surface disease. Arch Ophthalmol 1983; 101: 1284-7.

${ }^{9}$ Nelson JD and Wright JC: Conjunctival goblet cell densities in ocular surface disease. Arch Ophthalmol 1984; 102: 1049-51.

10. Tseng SCG, Hirst LW, Maumenee AE, Kenyon KR, Sun T-T, Green WR: Possible mechanisms for the loss of goblet cells in Mucin-deficient disorders. Ophthalmology 1984; 91: 545-52. 